\title{
The Potential of Vā Part 4: Methodology of Lala- Vā
}

\section{Abstract}

The article presented is part of a series of chapters that composed an exegesis, submitted in fulfilment of the requirements for the degree of Doctor of Philosophy. The series is a narrative of discovery through practice-led research. Each article reveals its purpose and significance that leads into the next series, which then eventuate to that final design proposal.

The exegesis is presented in this format, to break down the components that assisted in practice-led research. Each article can be read and unpacked on its own as a learning tool. The purpose of this edited series is for the exegesis to be more accessible and adaptable creatively to those being introduced to practice-led research.

The Potential of Vā Part 4: Methodology of Lala-Vā, presents the methodology of Lala-Vā to approach the research design. Archival research, current museum displays,

participation

and 
documentation, and experimentation are the sections that are explored within this methodology. Lalava and lalaga- the two different kinds of traditional practice used to address the research question- are outlined here as well as the strengths and weaknesses of these approaches.

\section{Methodology- Lala-Vā}

In her thesis Toluta'u (year) states:

Remember the path you have travelled and if it is a hazardous path the you should turn towards a path on which it is smoother to journey. This PhD charts unfamiliar waters, yet it also journeys along the same hala toka kovi (a rough road) or hala toka lelei (a flat road) that the hou'eiki fafine (Tongan women) who form its focus experience (Toluta'u, 2015a, p. 39).

Like the migrations of these hou'eiki fafine (Tongan woman) to other countries described by Toluta'u, I did not undertake this journey knowing the outcome of my destination, but like them, I knew clearly the purpose of my journey. In this regard, Toluta'u reminds us of William and Ormand's (2010) assertion that research is 'a process of seeking explanation and meaning' (pg.1). As such, we may employ it when we either seek to generate new knowledge or 'make a contribution to human experience' (Scrivener, 2000, p. 6). In such instances that contribute to human experience, we 
deal with judicious questioning rather than simply re-orchestrating facts (Toluta'u, 2015a).

\begin{tabular}{|c|c|c|}
\hline PARADIGM & METHODOLOGY & METHODS \\
\hline Practice- & Lala-Vā & Interviews \\
Led & & Archival research \\
Creative & & Current Museum \\
Production & & displays \\
& & Participation and \\
& & documentation \\
& & Experimentation: \\
& & Lalava \& Lalaga \\
\hline
\end{tabular}

\section{Paradigm}

The research design for this article may be understood on three layers. I begin with its paradigm as the first point. In practice-led research it is useful to consider what Toluta'u (2015) describes as a subsection of qualitative research that is supported by Scrivener (2000) who calls this Creative Production Research. This kind of review he defines as 'inventive and imaginative and realised through and artefacts'(Scrivener, 2000, p. 15). Scrivener proposes that such research projects have distinctive norms that separate them from research that might be defined as problem solving in their orientation. In her thesis, Toluta'u (2015) describes 
how Scrivener (2000) sees the following as the norms of Creative Production Research:

- Artefacts are produced. These are not byproducts of the research or illustration of knowledge. Instead, Scrivener says, they are objects of value in their own right and may be understood as objects of experience.

- Artefacts are original, in a cultural context. By this Scrivener means the research reflects culture, and concerns and interests are manifested within the creative production. $\mathrm{He}$ addresses the idea of originality by noting that whilst the creative outcomes may have precedents they are not derivative or imitative of others work.

- Artefacts are a response to issues, concerns and interests. The work is not necessarily the solution to the problem, instead it can be a response expressed through one or more artefacts.

- Artefacts manifest these issues, concerns and interests through the process of creative production.

- The issues, concerns and interests reflect cultural preoccupations. In the instance of this thesis 'cultural' is located within Tongan epistemological constructs.

- Artefacts contribute to human experience. 
- As contributors to human experience, artefacts are more important than the knowledge embodied in them (Toluta'u, 2015a, p. 40).

Therefore, this research, like Toluta'u's may be understood paradigmatically as a practice-led creative production inquiry because, through such positioning, the researcher prioritises the role of artefacts and the thoughtful practices that create them. Furthermore, Toluta'u positions her research as a creative cultural expression and contribution to human experience (Toluta'u, 2015a).

\section{Methodology}

The methodology is the second layer to the research design. By methodology I refer to the allencompassing approach to the research that is more than a discussion of methods used in its explication. Therefore, a consideration of methodology is shaped by cultural concepts and theories that underlie the tools and processes used in developing the project (Toluta'u, 2015a).

\section{Lala-Vā}

This article is located inside a Sāmoan epistemological framework. Because it is concerned with ways of being, knowing, and doing, methodologically it composes certain traditional Sāmoan approaches to accessing, processing and 
creating knowledge. Through this practice-led creative production 'we may encounter certain approaches and structures that resonate with views of heuristic and action research' (Toluta'u, 2015a, p. 40). The project's design is founded on the views of Lala-Vā. Lala-Vā is based on the concepts of fa'aSāmoa.

Since this research is a 50:50 combination of writing and practice-led creative research, the crossfertilisation between explorations of theory and experimental studio methods is crucial. I am currently developing systematic cross-overs between the reading of theoretical texts, archival research, documentation, and experimental approaches.

My research methodology is the Lala-Vā of these methods, which include interviews that allow me to draw on different knowledge systems and concepts, and designing and making explicit reference to Pacific traditions, knowledges, and cultures. In this project, I align myself with standpoint epistemologies, which emphasise the diversity and situatedness of knowledges (Gegeo \& WatsonGegeo, 2001, p. 58). They argue that any knowing is always a knowing from a certain perspective, and that this perspective needs to be made explicit (Gegeo \& Watson-Gegeo, 2002).

Sāmoan values, beliefs, history and oral narratives are the foundation for this research. In addition, the lalava and lalaga form the basis for understanding 
traditional construction within the research. In utilising the traditional art forms of lalava and lalaga, with the theoretical concept of vā, it transforms the Lala-Vā Model as a portal and cultural lens. This provides a foundation from which the researcher can analyse, describe, explain and critique the data collected for this research project located within an indigenous paradigm.

From the beginning of this research, the need to understand existing forms of cultural spatiality in New Zealand-based communities (specifically diasporic Sāmoan and Pacific people living in South Auckland) was an important driver in the development of my methodology. The Lala-Vā methodology is a method I designed to look at the research through a Pacific lens. It is key in conceptualising the values and beliefs of our Pacific people and specifically the blended Pacific communities here in Aotearoa/New Zealand. This Lala-Vā methodology is with respect to exhibiting my own creative work as part of the research.

Considering forms of display was crucial, because the relationship between modes of observation and engagement of these communities with my exhibit was an important factor that could determine success or failure of my design proposal. In my investigation of the potential of vā relationships for the design, I surveyed and documented forms of display, from the past to the present, including spaces and objects that my participants shared with 
me. All forms of exhibition of Pacific items, and all ways in which they could be viewed, were principally included and seen as worthy of analysis.

I mediated the shift between past and present through a reflection on the methodology and concept of the Lala-Vā Model; referencing the lalava/lalaga patterns that are metaphorical and physical ties to cultural knowledge advocating balance (Tohi, 2006). For my project, the balance of understanding past and present displays, and their sometimes conflicting aims, was important; it would help me select and develop appropriate modes of showing, learning from past Sāmoan andPacific exhibitions as well as present public museum exhibitions and displays by Pacific communities. At the same time, the potential of 'stirring the vā' as a driver for change remains an important concept.

Further to this investigation, I wanted to design an intervention within my community, and to display and create spaces of identity and multiple identities. The relational space created in my project is aimed at all cultures, religions and members of the community; a space or creative collection for those who may feel disconnected from their own Pacific identity in the diaspora.

I wanted to create a space that is accessible to all, but specifically the Pacific community, and speaks of blended identity to create an environment of change and awareness. A design that references and speaks to ethnicity, culture, and race, blending 
them to describe the society we live in. I wanted this design to evoke the way we think about space and our constantly changing Pacific diaspora communities.

The Lala-Vā methodology of these construction methods was discussed in the last section. The LalaVā methodology of the project describes the design practice. Studio methods utilised various approaches, including photography, documentation, experimental approaches, and collaborative concepts from interviews. My research methods included interviews, which allowed me to draw on different knowledge systems and concepts, designing and making reference to Pacific traditions, knowledges, and cultures. Those whom I interviewed are persons from blended backgrounds, who identify themselves as multicultural and were open to visual documentation of the space/s they inhabit. Most of the informants affiliate with the term diaspora, and explained their individual conceptions of the term.

\section{Impetus}

When I consider the concept of fa'aSāmoa, I am reminded that I grew up in Aotearoa/New Zealand with parents who migrated from the Pacific Islands in search of economic stability. The projected growth of these Pacific communities living in Aotearoa/New Zealand over the coming decades means that the politics of place and identity will become even more 
significant, and will add to the complexity of culturally diverse societies in a globalised world. The need to document their stories became an artistic concern for me as a Pacific woman born and raised in New Zealand. I was always curious about the identity experience of blended Pacific women, about how they adapted to and integrated with Aotearoa/New Zealand culture, and what that change meant for their identity, spatiality, cultural practices and the way that they raised the next Pacific generation outside of the Islands. There is very little research and documentation on blended Pacific diaspora and their identity and I felt it was important to contribute to this area of research using spatial design practice as a mode of retelling stories that had been undocumented.

\section{Extension}

Although my formative work had dealt with the potential of vā for a diasporic Sāmoan community living in Aotearoa/New Zealand, in this article I wanted to extend my consideration to blended Pacific communities residing in Aotearoa/New Zealand. I feel the potential of vā has more to offer, not just for a Sāmoan community, but that it can be adapted to other Pacific cultures, especially those that are blended. It is important to extend the source of information in order to move the research focus beyond a cultural binary. 


\section{Methods employed in the second, creative phase of the research}

The methods employed in this phase included:

- Indwelling

- The designer's journal

- Photography

A number of methods were employed in the second phase of the research and although they are discussed below under separate headings, they did not operate as disconnected components but instead as a Lala-Vā of components. They functioned in creative collaborations to advance my design thinking. Mostly the methods I used in this phase may be seen as an 'indwelling', a process mediating between my journal, photography, and designing exploratory artifacts (Toluta'u, 2015a, p. 46).

Indwelling

Toluta'u defines indwelling:

as a phase of the research and artistic process where the artist/researcher reflects on and immerses herself in the depth of her creativity and inner spirit. This is done in order to unravel deeper meanings and interpretations of natural and social realities (Toluta'u, 2015a, p. 47). 
Like Toluta'u, in designing the creative component of this research, I 'felt' the stories told by the participants and reflected upon their content. This is because the works I created were both poetic and 'documentary'. When I considered the participants' talanoa I was not 'editing' for influence. I was trying to draw to the surface the essence of the person, and the relationship between her blended identity and the spatiality around her. To do this, I immersed myself in her recordings and my photographic images of the objects and spaces.

I was 'indwelling' of her talanoa and used this lens to visualise and capture the images. These images were a reflection of the talanoa; small recollections that captured both a narrated memory and the identity of the participant.

This intuitive process of 'indwelling' involved a form of immersive contemplation that led to creative considerations of image, colour and composition that were critically reflective.

The designer's journal

Marshall and Rossman (2014) claim that a designer's journal employs subjective structures of data collecting and processing. It merges elements of 'the real inner drama of research, with its intuitive base, its halting time-line, and its extensive recycling of concepts and perspectives' (p. 15). Newbury (2001) adds that the journal is 'a selfreflexive and media literate chronicle of the 
researcher's entry into, engagement with and departure from the field'.

During the course of this project I used designers' journals as records and a location for thinking and fine-tuning ideas. In the development of the design process, thinking was processed as sketches and notes. Drawing connections, note-taking, and the design of spaces were the type of thought processes in my designer's journal.

\section{Drawing connections}

I used my journal as a way of drawing connections from the literature to the methodology of the research. This was a physical visual communicator, and the imagery enabled me to make, communicate and draw connections between the text and the creative process. This is significant in how I built ideas. Rough drafts can function as a form of shorthand thinking where thoughts can be trailed and considered quickly, then modified or excluded. 


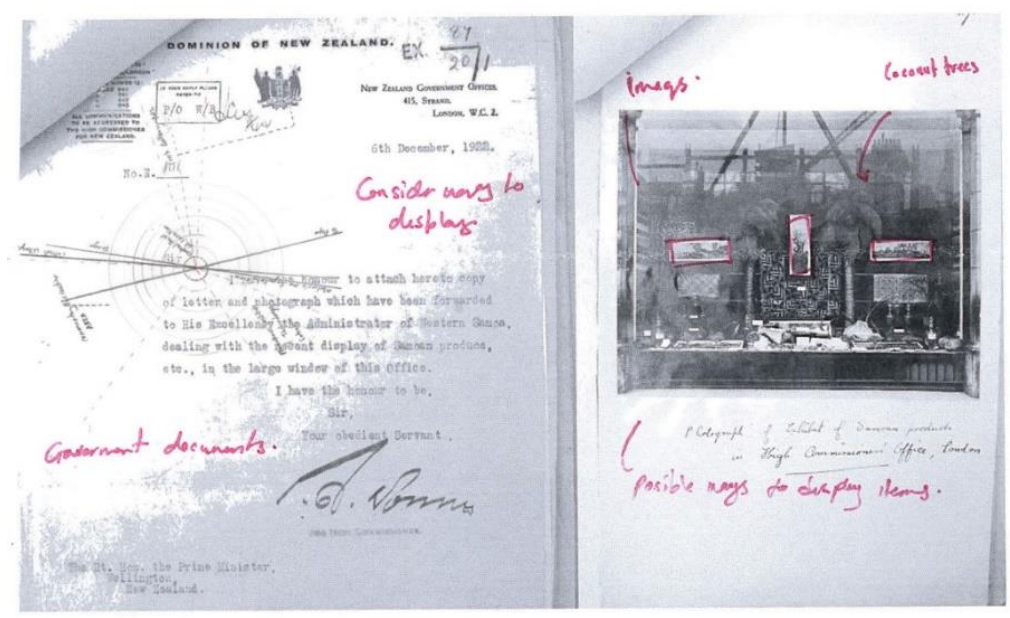

Simati, B. (2015). Page from my designer's journal.

Note-taking

Note-taking was crucial in keeping all of my thoughts archived. Note-taking would occur most when talking to people about exhibition ideas I was considering for the design. An annotated dialogue of conversations with supervisors, academics, family and friends, all of whom contributed vital ideas and solutions to problems and issues throughout the project.

\section{Design of spaces}

From the very beginning, my supervisors advised me to start thinking about exhibition spaces where I could exhibit my final design proposal. This was not new to me, as I had come from a background of Art 
and Design, where exhibiting in a gallery was a design process of its own. I used my journal to think about spaces beyond the gallery, space that could be accessible to my blended Pacific community, for whom this project is aimed at. My supervisor suggested AUT Ngā Wai o Horotiu Marae. At first, I thought it was an ideal location to exhibit. I drafted my way through potential ways of exhibiting, using photography that enabled me to think through concerns of lighting, placement, scale, and relationships between the viewer and the exhibited elements. Nearing the end of my design proposal, I concluded that the best way of distributing my design was to exhibit everything in the form of a book. There are many reasons why I wanted to present this work in a book format. Firstly, this research project as stated from the beginning was aimed for my Pacific community, if I think about this community, exhibitions and art galleries are usually aimed for a specific audience, and is a Western concept of exhibition. I didn't just want the work displayed for a certain time period then taken down, but rather I wanted to display the design in a way that was accessible and readable to a broad audience. I wanted to distribute my book, and gift it to many, as this was not something that was done on my own, but a collective project that belongs to the community. I wanted the research to speak with the design side by side, to reinforce the Lala-Vā; aspects of connection and belonging to fa'aSāmoa, 
the interconnection between two entities that are interdependent on each other.

Photography

Photography played a major part in the development of the research, and it was used in two ways. The first was documentation, a medium of recording, collecting and archiving material. The second was as a medium to capture and refine the spaces recorded from the interviews.

\section{Methods employed in the third phase of the research}

The methods employed in this phase include:

- Archival research

- Current museum displays

- Experimentation: lalava \& lalaga

- Mapping

- Participation and documentation

Archival research

- USA (Chicago:World's Columbian Exposition, 1893)

- UK (London: British Empire Exhibition at Wembley, 1924)

- New Zealand (Wellington: New Zealand Centennial Exhibition, 1940) 
Archival research was the starting point of this investigation. The goal was to collect and collate all of the information available from New Zealand archives concerning three Sāmoan fale that were exhibited in the USA (Chicago: World's Columbian Exposition, 1893), in the UK (London: British Empire Exhibition at Wembley,1924) and in New Zealand (Wellington: New Zealand Centennial Exhibition, 1940). The information was compiled in a database of written and visual documentation. From the documentation gathered, I found the visual images most informative, giving good insight into the forms of display. This knowledge challenged my perspective on how Pacific culture was viewed by others, from the 1890s to the 1940s. It also helped me appreciate the difficulties of space restrictions, the duration of travel, mis-readings and reinterpretations of items, and the view of Pacific displays generated from non-Pacific cultural perspectives, which cater to the interests of visitors to international and national exhibitions. Of the national and international exhibitions, I researched in Archives New Zealand, Wellington, the 1893 World's Columbian Exposition in Chicago was by far the most difficult to gather and source information about. Harry. J. Moors, a Michigan-born entrepreneur who resided in Sāmoa, set out from Apia to exhibit his work in the South Sea Islands as part of the 1893 Chicago World Fair. He wanted to represent a Sāmoan Village but his disloyalty to 
Malietoa (the then paramount chief of Sāmoa) led to Malietoa forbidding Sāmoans to associate with Moors (Bancroft, 1900). This meant his display would eventually be made up 'mostly of half-castes (people of mixed Sāmoan and Papalagi descent) and other Pacific Islanders, with only a few full Sāmoans who had been spirited away' (Salesa, 2005, p. 15). Moors managed to take aboard a huge cargo of Sāmoan objects, including a seventy-foot canoe of modern design (a taumualua), several smaller watercraft, and three large houses (fale). It is here, with the three fale, that the information becomes blurred; two book sources (Bancroft, 1900; Crocombe, 1973) claim that there were three fale, and one claims it was one knockdown Sāmoan House' (Furnas, 1945, p. 146). It is also still unclear whether one of the fale belonged to Mata'afa Iosefa, an exiled high chief of the Atua district, whom Moors befriended. Initially, I was so fascinated by Moors' approach to display and authenticity that for my own project I wanted these approaches to be clear and distinctive. Mata'afa Iosefa turned out to have also played a role in the preparation for the British Empire Exhibition (B.E.E) at Wembley, in 1924. From the communication between officials based in Britain, Sāmoa and New Zealand held in the archives, it appears that Mata'afa offered to build a fale for the New Zealand External affairs administrators who organised exhibits for the Empire Exhibition. He gathered 200 of his people as 
workers in Sāmoa and offered to erect it in Wembley. This offer was declined by the New Zealand colonial government, which had explicitly decided not to send any 'Native troupes' to Wembley (Johnston, 1999, p. 150). Instead, an Englishman, Mr. H. Charles Reed, a trader married to a Sāmoan chief's daughter, Masooi Reed, erected the fale at Wembley - not unlike Moors at the Chicago Exposition. However, Reed altered the construction to some extent to fit it to a site that was shorter than anticipated. The Ministry of External affairs requested that the Sāmoan exhibits be returned to New Zealand after the British Empire Exhibition, later to be displayed at the Dunedin Exhibition. Delay in the fale's disassembly by Reed, as well as a misunderstanding regarding a payment of $£ 300$ for the exhibits, meant the fale, at the time at least, remained the property of the British Administration (Department of External Affairs, 1924).

A third exhibition I researched at the Archives New Zealand was the 1940 New Zealand Centennial Exhibition in Wellington. The documentation indicates that the fale exhibited in the Wellington Centennial arrived from Sāmoa on the ship Tofua. Along with the fale, other Sāmoan exhibits arrived aboard ships, which were to be displayed at several exhibitions held in New Zealand, namely in Auckland, Christchurch, Dunedin as well as at the Hokitika Exhibition. Reading through the archives, I found it difficult to track the fale's journey since 
then. However, there is a document to show that towards the end of the Hokitika exhibition, it was advised that the fale be exhibited in the Wellington Museum (p. 4460). A search through Papers Past led me to a small extract from a newspaper article (15 May 1940) according to which the fale had been purchased by an Aucklander by the name of Mr. H. J. Kelliher. Kelliher intended to re-erect it on the island of Puketutu, in the Manukau Harbour, which he at the time. To this day, the fale stands on the Kelliher Estate.

\section{Current museum displays}

\section{Auckland War Memorial Museum}

The Auckland War Memorial Museum was the beginning of my investigation for current displays of Sāmoan and Pacific items. What was most attractive at first sight was the Māori gallery filled with significant artefacts. The display was a coherent journey from the history of Māori culture to a live cultural performance. The museum stores a generous collection of Sāmoan and Pacific artefacts. The individual Pacific displays within the Auckland Museum reflect the Pacific Island groups who live in Auckland and highlight different communities; objects such as tools and utensils for communal living, hunting, fishing and recreation to me failed to communicate their use and natural environment. The Pacific gallery, although generous in its volume, I felt lacked in materiality in emphasising the Pacific 
Islands artefacts. The Auckland Museum stores artefacts from Tonga, Fiji, Sāmoa, Kiribati, Niue, the Cook Islands, Vanuatu, the Solomon Islands and Papua New Guinea (Auckland Museum, 2011), but in my opinion the displays also create clutter and a 'busy' environment. Reflecting on the journey, I had to understand the many difficulties and restrictions curators must deal with when exhibiting such a large collection of Pacific items. I cannot fault the design concept, lighting, and craftsmanship of display units as all of these elements brought to life a somewhat imaginary voyage through the Pacific.

\section{Te Papa}

Te Papa is New Zealand's national museum, located in the capital city of Wellington; Te Papa is renowned for being bicultural, scholarly, innovative, and fun. The success of the museum is built on its relationships and ability to represent the New Zealand community. The Te Papa Museum, I felt reflected a more urban view of Pacific items on display. It was an honest take of the diaspora Pacific youth; it showcased the diaspora community and reflected their influence within the arts community through music, art and cultural festivals. Collage display units reflected the colourful nature of Pacific communities in Aotearoa/New Zealand, and how they are very much interconnected with one another. Te Papa also has in storage some of Sāmoa's most prestigious 'ie toga. These items, in 
storage, become 'lost' and forgotten by the public. The relations symbolised by these objects no longer in social use, become dormant and worthless. 'Museums are burdened with objects which do not fit and which therefore are rarely or never shown to the public' (Kirshenblatt- Gimblett, 2002, p. 60). Most museums are only able to exhibit a very small share of their holdings and in many cases not more than 10 per cent. This piece of information was an opportunity, a chance for my project to put on display Pacific items that have been archived, to reunite vā relations within the Pacific community. The Pacific items in storage were historical and held significant value to the Pacific diaspora communities; they maintained ancestry and traditional knowledges that would enable these communities to imbibe cultural connections.

Reflecting on contemporary forms of Sāmoan and Pacific displays, it is obvious that Māori and Pacific curators have in-depth knowledge of the items they display, despite working within the restrictions of galleries, institutes and museums. The items on display and in storage are well organised, categorised, described, and archived. However, while it is clear that these forms of display are aimed at education and tourism, Pacific communities, I feel, are disconnected from these institutions. To me, the thought of museums archiving artefacts that hold significant relations within the Pacific diaspora community is unsettling. If lalava is about 
balance and change, lalaga is about tying these different entities together in various ways. In contrast to the Westernised views of knowledge commonly held within the walls of the museum, my plan of intervention is a proposal that Pacific communities have access to these archived artefacts. My project aims to interlock the threads of meaning and the threads of vā relations active within the blended Pacific community.

Experimentation: Lalava \& Lalaga

As stated in the Traditional knowledge: lalava \& lalaga' section, the information provided by Potauaine (2011) about lalava had potential regarding the binding of directional lines in the mapping process. For this research, I initially reviewed the processes of my Masters thesis specifically the use of materials that have no obvious relation to Pacific construction materials. Testing different variations of spatial relationships, I began to form my own language of lalava. I paid close attention to what happens in the process of binding together cotton and steel rods to produce spatial models. I observed the properties of the materials (e.g., stability and fragility), how they react, and what the resulting spaces look and feel like. I then took photos of the models created and adjusted light settings in Photoshop to explore the spatial properties of different configurations. I then moved on to lalaga, this time focusing of the 'ie tōga, finding 
spatial relations that pertained to the 'ie togga by means of photography, scanning, and lighting.

Reflecting on both of these processes, it was interesting to note the fragility and fluidity of the materials. The feedback I received from my community elders and participants made it clear to me that it was difficult for others to associate the metaphorical relationships, and spaces of my experimentation of lalava and lalaga; meaning my conceptual design aesthetic was not communicating well with my community. I had to ask myself, 'What was the potential of vā within this experimentation?' The physical manifestation of both of these metaphors was not leading me to a design proposal. I therefore decided to move away from the materials, and to engage with my community to find other means of using lalava and lalaga in spatial relationships within the vā.

\section{Mapping}

Mapping was a method of graphically locating the space of my diaspora participants in relation to the Pacific Islands they associated with. I used mapping to visualise and consider ways of locating and presenting my design proposal. It aided me in thinking about the general approach. However, this was an initial consideration because this framing was significantly altered by the nature of the talanoa with each participant. The lines and connotations in my mapping were checklists or accounts of the 
spaces I might be wishing to capture, or actions, themes and directions for myself.

Participation and documentation

The Pacific arts community is very much alive in the diaspora, each year celebrating Pacific culture and showcasing a range of crafts on display. From the Otara South Auckland markets to the Waitakere Pacific Arts and Community Trust, Pacific culture is noticeable in Aotearoa/New Zealand. Part of my methodology was to become involved with my surrounding communities and to participate in workshops throughout the year. My participation and documentation adopted the method of lalaga because, like [in] a fine mat being woven, the strands of Sāmoan history, fa'aSāmoa and Sāmoan contemporary livings, and their interaction with 'others' interconnect to inform Sāmoan identity' (Anae, 1998b, p. 1). Thus, with my involvement and accounts (interconnection) of the many events and activities (threads) offered for Pacific peoples, this article acknowledges and connects to the larger body of the Sāmoan diaspora (Sāmoan identity). I hope that the information collected here helps recognise the Pacific communities in Aotearoa/New Zealand, and what they offer as diaspora peoples.

Rosanna Raymond

Colab, in conjunction with AUT University, invited Rosanna Raymond to be their artist in residence. As 
part of the programme, Raymond held a full day workshop, which I attended, using the AUT Manukau Campus sculptures to investigate the tension between language, voice(s), the written word, the spoken word, the body and material objects. Rosanna Raymond is a woman of many talents, but she is first and foremost an artist. Raymond is a well-known figure in the New Zealand Pasifika movement, being an integral practitioner in performance, poetry, art installation and exhibition. The workshop was to create a series of performative interventions revealing, activating and interplaying with the hidden voices and stories imbued in the AUT Manukau Campus sculptures. Raymond held quick sessions where we were given a few minutes to describe the sculptures in a list of words. In relation to my practice as a designer it forced me to see beyond the physical object and read deeper into the meaning of form. The reading of patterns on the sculptures was a meaningful journey as it provoked feelings of my own identity. Raymond's workshop covered creative expression using Pacific stories and cultural objects; I found a creative voice within myself, being expressed through words of identity. This information fed directly into the introduction of this research, describing this project from my own perspective and identity as a member of the blended Pacific diaspora. 


\section{Rick Pearson}

My next point of investigation was difficult in that I needed to figure out what was the physical spatial design of my proposal. Having done research on exhibition and displays it was appropriate to meet an architect behind these curated displays. Rick Pearson is an architect who specialises in exhibition and museum design; his expertise in this area gave me two important directions on how to begin the process of designing an exhibition. Pearson's first point of direction was beginning with knowing your material of display. Knowledge of the material meant an awareness of how to spatially create an environment. His second point was to document every item, and familiarise myself with the site of display, space restrictions, lighting, preservation of items and those not necessary to the display. Pearson made me critically think about the traditional forms of display. I constantly kept coming back to forms of display cabinets, lighting levels, space restrictions, but when I thought about my Sāmoan diaspora community I wondered whether these traditional forms of display would cater to their needs. What forms of display could actively communicate to this community? I didn't know the answer, however I knew the solution did not lie within a museum or gallery exhibition.

By this point in my research I had taken photos of my participants' homes, and the images were something I wanted to display, but there was 
something beyond the image that was hard to articulate and display. It was the artefacts themselves. How would I exhibit theses to a broader audience? How could I tie the exhibits from the museums together with the artefacts that existed in the community?

I knew I wanted to display Pacific artefacts, but what sort? I had to be more specific to items that were going to activate relations of location and identity, but these specific Pacific items were either held or stored in museums, or by the government.

\section{Mamas and Museums}

The South Auckland Pacific Arts Summit forum provided an opportunity for my practice to expand further from the museums and exhibitions and become involved with visual arts, forums, and literature in the community. Mamas and Museums was a workshop created by Kolokesa MāhinaTuailooks as part of the South Auckland Pacific Arts Summit. The aim of the workshop was to create mutual understanding and foster better communication between the museum sector and female Pacific fine artists. 'Mamas' from across New Zealand, representing a variety of island nations, were invited to exhibit their fine art and share information about the type and variety of art works they create and the materials they use. What was most interesting about Māhina-Tuailooks' workshop was the communication between the mamas and 
the representatives from Te Papa Museum and Auckland Museum who talked to us about the work they do with their respective Pacific collections. The conservation workshop sessions run by the conservators from both museums provided a safe place and mutual understanding for both parties, sustaining, distributing and contributing to Pacific knowledge.

For me, what was most successful about this event was the safe environment Māhina-Tuailooks provided for the mamas. The mamas spoke about their crafts and the difficulties of teaching this knowledge to the younger generation who were largely not interested. For most, this was their first time presenting their craft to an audience. The workshop was a success as it celebrated these mamas for their skill and knowledge, with each being very proud of the island they represented. Their stories resonated through their artefacts. It was this very aspect that I drew from my interaction with my participants. The stories told in their own language was something powerful and poetic that had to be shared. The artefacts didn't stand alone, they existed and came to life with the traditions and history that pertained to them. The interconnection of the artefact and the story teller was the vā, 'not space that is separate but space that connects'(Wendt, 1996, p. 1). The relationship of the artefact and the storyteller was a concept that had to be carried through to my final design proposal. 
Pasifika \& ASB Polyfest

People from many Pacific nations grace Aotearoa/New Zealand with their rich cultures and spiritual traditions expressed in many ways including music, song, dance, prayer, language, visual art, performing arts and traditional arts. Involvement with the Pacific performance sector was the next stage in the methodology.

Pasifika is a Pacific Islands-themed festival held annually in Auckland. The festival presents a wide variety of cultural experiences, including traditional Pacific cooking and performances ranging from Sāmoa to the Māori of New Zealand. A second event, the ASB Polyfest, is South Auckland's most iconic Pacific event. The festival is a celebration of Māori and Pacific Island communities through cultural song, dance, speech and art. Every year, the festival delivers healthy competition between secondary schools celebrating diversity and cultural identity. Reflecting on my documentation of both festivals, Pasifika and Polyfest, I couldn't help but feel the pride gleam from the sea of brown faces. The festivals, I felt, gave the youth pride in terms of their blended identities, but also acknowledged their peers and the relationships they share as Pacific diaspora. The community participation was incredibly supportive and accommodating of their cultures. The essence of what Pasifika and Polyfest provide is the wellbeing of cultural identity. This 
essence was what I wanted to seek in the 'participation and documentation' method.

My involvement as a South Auckland resident, member of the Weymouth Congregational Church of Sāmoa, church youth participant, and recipient of the Manukau AUT Scholarship, has allowed me to view our community from these different vantage points and analyse the successes of each event. For my project, I wanted to take a few qualities of a festival to manifest in the display of artefacts, a display of artefacts provided from the blended Pacific diaspora community and for the community, a display that centres on the celebration of these artefacts.

More significantly, I have always joined, or been a part of the social gatherings held for the Pacific communities in Auckland. To document the occasions in the past few years has justified the importance of cultural gatherings for me, and the need to sustain these different and diverse knowledges within the blended Pacific diaspora community. The celebration of the ASB Polyfest, as well as the Pasifika Festival, is hugely popular and brings forth blended identities from Pacific communities. These events inspired my project to take on the performative and creative characteristics that both of these events succeed through. They prevented me from focusing solely on the display of an exhibition, and inspired me to embrace the performativity that activates vā 
relations. The performative aspect in the display of artefacts lies within the story that pertains to each significant piece. To achieve this, the community must be involved in the production of the display. My intention is to create a space where the community put forth their most precious family artefacts that have history and significance to the 'aiga and would be beneficial to document and archive for future generations. These artefacts will not be taken away or tampered with, but treated with respect and shown in the light they deserve. An important aspect in this documentation is locating which part in the Pacific Islands these artefacts originate from, and the authenticity of each piece. This will also be a form of filtering the artefacts. The performative element, is where the family themselves either submit a written statement on the artefact, or agree to be video documented speaking about the artefact on behalf of their family. This brings about the question, 'What sort of spatial environment will allow me to archive these artefacts from the community, and display these artefacts for the community?'

\section{Conclusion}

In this article, talanoa, together with digital and spatial design approaches weave together a union of traditional knowledge, Sāmoan epistemology, and research-informed design. The research proposes a new way of approaching spatial design that is 
essentially Pacific. By recording the stories through talanoa this research has both preserved narratives and proposed a new, more culturally respectful way of archiving Pacific artefacts. This form of participation and documentation is not photographic but poetic. As such, the research also offers a contribution to international discourse surrounding indigenous people. Therefore, both the content and the style of the work may prove worthwhile for Pacific Studies, family history, humanities research, and developments in art, and spatial design disciplines.

This article has discussed the paradigm, methodology and methods active in the exposition of the research. Located paradigmatically as creative construction research, the exegesis is concerned with imaginative and inspired thinking, understood through and in artefacts (Scrivener, 2000).

Methodologically, the research is inspired through a unique application of Lala-Vā that is, by extension of theories. The stages and considerations of this methodology has enabled me reflect deeply on the interviews from the participant. Lala-Vā has also offered a culturally appropriate and responsive framework for working closely with the blended Pacific participants. In practice, a number of methods have been essential to developing the research. 
Having now discussed the research design method, the concluding article of the research brings about the actual physical design, and thinking in relation to the critical ideas that shaped the physical appearance. 


\section{References}

Auckland Museum. (2011). Pacific Lifeways.

Retrieved from http://www.aucklandmuseum.com/?t=298

Gegeo, D. W., \& Watson-Gegeo, K. A. (2001). "How We Know": Kwara'ae Rural Villagers Doing Indigenous Epistemology. On The Contemporary Pacific: University of Hawai'i Press. Retrieved from http://muse.jhu.edu/journals/contemporary_pacif ic/v013/13.1gegeo01.html

Gegeo, D. W., \& Watson-Gegeo, K. A. (2002). Whose knowledge?: Epistemological collisions in Solomon Islands community development. The Contemporary Pacific, 14(2), 377-409.

Kirshenblatt- Gimblett, B. (2000). Exhibiting the Other: Museums of Mankind and the Politics of Culture Representation. Reflections.

Kirshenblatt- Gimblett, B. (2002). The Dematerialization of culture and the DeAccessioning of Museum collections. Museum International, 54(4), 58-63.

Scrivener, S. (2000). Reflection in and on action and practice in creative-production doctoral projects in art and design. Working Papers in art and design, 1. Tohi, F. (2006). Sopolemalama Art of lalava. Retrieved 19 March 2010, from http://www.lalava.net/nav.html

Toluta'u, T. K. (2015a). Veitalatala: Maitanga 'o e Talanoa. Auckland University of Technology, Auckland University of Technology. 
Toluta'u, T. K. (2015b). Veitalatala: Matanga 'oe Talanoa. Auckland University of Technology. Wendt, A. (1996). New Zealand electronic poetry centre. Tatauing the post-colonial body, span 42-43, 15-29. Retrieved from http://www.nzepc.auckland.ac.nz/authors/wendt tatauing.asp. 